\title{
Research Paper: Leisure of People With Multiple Sclerosis: A Content Analysis
}

\author{
Seyed Mohammad Sadegh Hosseini', Mohsen Sarhady ${ }^{1}$, Sahar Nurani Gharaborghe ${ }^{1 *}$, Mehrdokht Mazdeh ${ }^{2}$ \\ 1. Department of Occupational Therapy, School of Rehabilitation, Hamedan University of Medical Sciences, Hamedan, Iran. \\ 2. Department of Neurology, School of Medicine, Hamedan University of Medical Sciences, Hamedan, Iran.
}

Citation: Hosseini SMS, Sarhady M, Nurani Gharaborghe S, Mazdeh M. Leisure of People With Multiple Sclerosis: A Content Analysis. Iranian Rehabilitation Journal. 2017; 15(1):23-30. https://doi.org/10.18869/nrip.irj.15.1.23

: https://doi.org/10.18869/nrip.irj.15.1.23

Article info:

Received: 25 Oct. 2016

Accepted: 05 Jan. 2017

\section{Keywords:}

Multiple sclerosis, Qualitative study, Leisure activities

\section{ABSTRACT}

Objectives: Leisure is a domain of life that is very important, particularly for people with neurological disorders. However, due to social and cultural differences, leisure activities have not been studied extensively. The aim of this study is to determine the different factors influencing leisure activities among people afflicted with Multiple Sclerosis (MS) within the framework of Iranian culture.

Methods: We used two independent qualitative studies: 1) interviews conducted with 11 professional that related to these patients and 2) open-ended questionnaires that were completed by 49 patients with MS. Qualitative and quantitative analyses were performed on the data obtained.

Results: Six factors were extracted from the analyses on each of the two studies: social, individual, physical, art-cultural, spiritual/religious and educational.

Discussion: Our results suggest that the leisure activities of the MS patients are influenced by six factors. We suggest that studies concerning leisure activities of Iranian MS patients should consider these factors.

\section{Introduction}

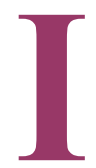

$\mathrm{n}$ accordance with the Model of Human Occupation, it can be said that humans are complex systems and are related to the environment [1] Each system consists of three domains: leisure, work, and activity of daily living. The balance between these domains is one of the most important aims and practices of Occupational Therapy [2]. If a person's leisure activities are not adequate, it might affect the functioning of other domains. One defini- tion of leisure is "non-obligatory activity that is intrinsically motivated and engaged in during discretionary time, that is, time not committed to obligatory occupations such as work, self-care, or sleep" [3]. Thus, leisure is a part of modern life such that any increase in social awareness leads to an increase in people's interest to contribute to it [4] It is also significantly connected with public health [5].

Nonetheless, leisure may encounter restrictions by way of a variety of disorders. As such, Multiple Sclerosis (MS), a neurological disorder, may restrict leisure activi-

* Corresponding Author:

Sahar Nurani Gharaborghe, MSc.

Address: Department of Occupational Therapy, School of Rehabilitation, Hamedan University of Medical Sciences, Hamedan, Iran.

Tel: +98 (81) 38381571

E-mail: saharnurani@yahoo.com 
ties [6]. Patients with MS prefer to consume their energy by performing more obligatory activities than leisure activities, thereby neglecting the latter [7]. In addition, personal problems and environmental factors may challenge the ability of MS patients engaging in leisure. The prevalence and incidence of MS patients were reported to be 54.51 and 5.87 per 100,000 respectively, in Iran [8]. The ratio of MS prevalence in females to males is 3.34: 1 .

There has been controversy regarding the mode of measurement of leisure and determining factors with variability surfacing among studies [9-11]. Packer et al considered instrumental, social-cultural, physical, and passive dimensions for the estimation of leisure [11]. Another study revealed three factors: achievement, social and time-out [12]. Leisure participation scale for women with chronic fatigue disorder includes three categories: physical, social, and passive [10]. In a different study on healthy persons, educational/creative factor was added to measure leisure [13].

In addition to the differences in the factors, dimensions, and structure of leisure, leisure also depends on the cultural and social structure. In the past decades, cultural differences have led to inconsistency in explaining the concept and factors influencing leisure. For example, in American culture, the emphasis is on individualism, freedom, human rights, happiness, and independence. However, in Asian cultures, where individuals live in groups and hierarchy, group harmonies and interdependence are more important [14].

Some research studied leisure among different ethnic groups in a country. Culture can be affected by selection, participation, and consequences of leisure. Investigations on American ethnic groups showed diversity in interests and participation in leisure activities. For example, Hispanic/Latino people often participate in music and dance while Asian-American groups usually select activities such as traditional cooking, arts, tile games and board games. In contrast, African-American people participate in running, woodwork, and quilting as leisure activities [15]. In a recent qualitative study by Hosseini et al, which is in line and parallel to our study, $34 \mathrm{MS}$ patients participated in semi-structured interviews. The result of their study showed six domains of leisure: spiritual/religious, educational, individual, social, physical, and art/cultural [16].

While investigating culture, perception, and belief of people, qualitative research helps in clarifying hidden aspects of the concept $[17,18]$. It is better to conduct a study of people's leisure activities in social, cultural, spiritual, phys- ical, personal, and temporal context from a holistic view of Occupational Therapy [3]. Thus, the aim of this study is to identify items of leisure and the factors influencing it among Iranian MS patients, keeping in mind their culture.

\section{Methods}

This qualitative research was based on the content analysis of two different parts. In the first part of the study, MS patients $(35.12 \pm 8.358$ years old) were selected by convenience sampling to complete an open-ended questionnaire $(\mathrm{n}=49)$. Forty-two of the respondents were female, $71.4 \%$ married, $49 \%$ housewives, and time to diagnosis was 1 to 21 years. This questionnaire had a query: "Please, if possible, write below 10 activities that you do during your free time or leisure". This part of the research took place at the clinic. Demographic information of the patients is shown in Table 1 .

The second part of the study was performed with the help of unstructured face-to-face interviews conducted among 11 specialists: 2 occupational therapists, 2 physical therapists, 2 neurologists, 2 psychologists, 2 nurses, 1 audiologist, and 1 coordinator of MS Society. They were all selected by snowball sampling. Their work experience with regard to MS was between 2-24 years. Each specialist was interviewed for 20-40 minutes. After explaining the aim of the study, the interviewer requested each specialist to describe the leisure activities of MS patients and also the leisure activities that they usually recommend to their patients.

Data from the two parts of the study were analyzed using the Graneheim and Lundman qualitative content analysis [19]. Interviews of patients and specialists were recorded and transcribed verbatim. In the beginning, content analysis was performed by reading the transcribed data pertaining to the specialists and the patients separately. Thereafter, portions of the text containing similar content were marked as meaning units. Consequently, these meaning units were condensed. Categories and subcategories were created from codes. This process, which was performed by the study team members, is presented in Table 2. Open-ended questionnaire data were also extracted as codes in the result.

\section{Results}

\section{Open-ended questionnaire}

Data from the 81 open-ended questionnaire activities were divided into five factors due to the overall similarity to interviews with the patients,. The first factor was the physical factor and included as many as 52 items 
Table 1. Demographic Information of MS patients

\begin{tabular}{|c|c|c|}
\hline & Characteristics ( $n=49)$ & \\
\hline \multirow{3}{*}{ Age } & Mean \pm SD & $35 \pm 8$ \\
\hline & Max & 19 \\
\hline & Min & 54 \\
\hline \multirow{2}{*}{ Gender } & Female & 42 \\
\hline & Male & 7 \\
\hline \multirow{4}{*}{ Marital status } & Unmarried & 11 \\
\hline & Married & 35 \\
\hline & Separated & 1 \\
\hline & Widowed & 2 \\
\hline \multirow{3}{*}{ Time of diagnosis } & Mean \pm SD & $4 \pm 6$ \\
\hline & Max & 1 \\
\hline & Min & 21 \\
\hline \multirow{4}{*}{ Educational level } & Illiterate & 1 \\
\hline & Less than high school diploma & 28 \\
\hline & Academic & 14 \\
\hline & Graduate & 5 \\
\hline \multirow{5}{*}{ Work } & Employed & 14 \\
\hline & Unemployed & 9 \\
\hline & Retired & 1 \\
\hline & Housewife & 24 \\
\hline & Student & 1 \\
\hline
\end{tabular}

SD: Standard Deviation

Ilranian Rehabilitation Journa

such as performing exercise at home, walking, doing yoga, and swimming. The second factor was social and included 138 items like attending parties, traveling, and shopping. The third factor, which was individual, had the maximum frequency. It included 145 items such as watching television, listen to music, reading, gardening, and so on. The fourth factor was educational/creative activities and it had the minimum frequency. The frequency of this factor amounted to 38 items, which included tailoring, knitting, providing school education to children, etc. The last factor was religion and included
42 items like attending Quran classes and participating in religious ceremonies. We think the reason the individual factor had the highest frequency was that, in this part of the study participants remember and recall most objective items that are found in this factor, like watching $\mathrm{TV}$, and reading a book.

\section{Interviews with specialists}

Seventy-four activities, which were derived by means of content analysis of data obtained from this part of

Table 2. An example of analysis

\begin{tabular}{ccc}
\hline Meaning Unit & Condensation & Codes \\
\hline $\begin{array}{c}\text { I often recommended some exercises like yoga, } \\
\text { swimming to patients }\end{array}$ & Exercises such as yoga and swimming & Exercise in gym salons \\
$\begin{array}{c}\text {... Know the MS patients stay at home and carry } \\
\text { out usually sewing }\end{array}$ & Carry out sewing at home & Sewing \\
Journey to Mashhad and Qom & Religious travel & Travel
\end{tabular}

Iranian Rehabilitation \ournal 
study, were divided into five factors. The first factor was the physical factor that had a frequency of 34 and included activities such as swimming, walking and exercise. Five experts stated each of these activities. The second factor was social and included 20 activities such as going to the park, traveling, and getting together with friends. The third factor was individual and included 28 items like playing mobile games, listening to the radio, and solving a crossword. The next factor was educational or creative, with the maximum frequency of 42 items from 25 activities like knitting, painting, and carpet weaving. The last factor was religious and included 9 items from 4 activities: worship, going to holy shrine, pray and reading of Quran. It seems that the high frequency of physical and educational/creative factors was due to recommendations of the specialists to their patients.

\section{Combination of the two parts}

The qualitative and quantitative analyses of the two parts of the research are shown in Table 3. As observed in the previous part of this study, the items were categorized into six factors: spiritual/ religious, art-cultural, individual, social, and physical. Then, categories were divided into subcategories. Physical and social were divided into indoor and outdoor activities, and individual and spiritual/religious were divided into active and passive activities. The two other factors remained without subcategories.

Table 3. Overview of content analysis with their frequency

\begin{tabular}{|c|c|c|c|}
\hline Codes & Subcategory & Category & Theme \\
\hline $\begin{array}{l}\text { Exercise at home (30)/Exercise with Bicycle Stable (5)/Dancing } \\
\qquad(4) / \ldots\end{array}$ & Indoor (49) & \multirow[t]{2}{*}{ Physical (150) } & \multirow{10}{*}{$\begin{array}{l}\text { Leisure activi- } \\
\text { ties (1150) }\end{array}$} \\
\hline Walking (33)/Swimming (21)/Going to yoga class (14)/... & Outdoor (101) & & \\
\hline $\begin{array}{l}\text { Going to the party (66)/Talking on the telephone (21)/Family } \\
\text { gatherings (19)/... }\end{array}$ & Indoor (185) & \multirow{2}{*}{ Social (452) } & \\
\hline $\begin{array}{l}\text { Going to park (42)/Going out with friends (11)/Volunteer } \\
\text { work (10)/... }\end{array}$ & Outdoor (267) & & \\
\hline $\begin{array}{l}\text { Playing with cell phone (14)/Gardening or Growing flowers } \\
\text { (13)/Doing nonobligatory home activities (6)/... }\end{array}$ & Active (83) & \multirow{2}{*}{ Individual (311) } & \\
\hline $\begin{array}{l}\text { Watching television (73)/Listening to music (55)/Reading } \\
\text { books }(53) / \ldots\end{array}$ & Passive (228) & & \\
\hline $\begin{array}{l}\text { Participating in religious ceremonies (10)/Going to mosques } \\
\qquad(9)) / \text { Going to Quran classes (4)/... }\end{array}$ & Active (41) & \multirow{2}{*}{ Spiritual/religious (85) } & \\
\hline $\begin{array}{l}\text { Listening to religious dirge (7)/Reading Quran or invocation } \\
(16) / \text { Reading spiritual stories (1)/... }\end{array}$ & Passive (44) & & \\
\hline Knitting (19)/Tailoring (11)/Making cakes and pastries (9)/... & - & Art-cultural (122) & \\
\hline $\begin{array}{l}\text { Teaching child (8)/Going to computer classes (2)/ Doing vitre- } \\
\text { ous enamel (1)/... }\end{array}$ & - & Educational (30) & \\
\hline
\end{tabular}

Iranian Rehabilitation Journal

\section{Discussion}

Leisure can have a high impact on MS patients. The following statements of patients who were interviewed are evidence: "saves me from the noisy and hubbub world", "My spirit improved", "I was relaxed", "It takes less stress away", "I'm less angry in the day", "occupied in leisure help my mood”, " I'll be happy”, "when I perform (leisure) involve my mind and I do not think the disease", etc. It shows leisure has positive effects on a person, and its absence can increase individual problems.

The findings of the present study showed that the activities of MS patients were arranged in the order of most frequency to that of the least as follows: social, individual, physical, art-culture, spiritual/ religious, and educational. The results of this study are similar to a parallel study [16].

The social factor is significant because of the value of family structure, which is prevalent among Iranian communities and involves the support of an individual by family and relatives [20]. For example, when a person is unmarried, he/she stays at home with parents. Islam advocates maintaining interpersonal relations and helping others. The faith considers these values to have a positive effect on a person's moral structure [21]. In the interview, some of the patients said they had developed relations with other patients and helped them. One of the participants who walked with the help of an aid was keenly interested in the family and friends' gatherings 
because they provided a positive energy. Another reason for the high frequency of this factor was that most of the patients were married and were forced by their children and spouse to perform social activities.

In contrast, some of them did not like being part of gatherings because of physical disability. These events led to shame and reduced confidence, and they preferred not to be present during such occasions. However, social life is important in Iranian Islamic culture [22]. It is expected of MS patients as well as other people to spend most of their lives with others. Going to a party, represents the most common event of social life, which has also been mentioned in several studies [31-36].

Activities coming under the purview of individual factor can be carried out alone with personal objectives acting as a buoying force. Some patients during the interviews mentioned their interest in socializing with others. Apparently these patients perform individual activities more than others. Remarkably, some patients do not say to others about the diagnosis of MS, except their family. One of the reasons for this is social labeling in the culture."For example, one says high blood pressure, she tells I am not always this way, Sometimes I am after it gets cold. You know these people consider the disease bad in the culture".

It seems the cultural reasons as well as disabilities and psychological problems such as depression and anxiety can lead people to engage in leisure alone. Some of the participants said that they could not come out of the house alone because of disability and needed help from wife/husband or others. So they instead spend a lot of time at home alone. Wang used motionless factor in her research [30], and Lemmon considered solitary factor [31]. Another study considered selected passive factor. All of these factors may be similar to the individual factor of present study $[24,32,33]$.

The third factor, i.e., physical, is visible and tangible, and many patients in the study reported it. People who are still in the early stages of the disease are aware of the possible future of physical disabilities and put in efforts to maintain and increase their ability. People with disabilities are trying to restore their abilities. In the interviews with experts, on the other hand, almost all of them recommended sports and exercise for patients. A psychologist said: "I would recommend MS patient that instead of running that was not good for her/him, do swimming or aerobics. But all of them should be doing exercise"
The patients interviewed had no severe physical activities. Physical disabilities affect people's lives and are considered obstacles for a lot of activities, most importantly working. Favored physical activities for the MS patients were walking, swimming, and yoga. Fatigue was one of the major concerns of patients as it can affect all aspects of life including leisure time [34]. Interviewees reported that the above-mentioned activities would result in fatigue for them. It seems that one of the causes of the tendency of patients to perform these activities is recommendations from experts. But, two experts stated aerobic exercise as a leisure time physical activity was not appropriate. This causes the production of heat within their bodies and may result in inflicting further damage to patients' condition. Many other researchers have pointed out physical factors in their studies [23, 27, 28, 35, 36].

The fourth factor was named artistic-cultural as it consisted of creative activities. These activities were usually carried out by women, particularly housewives. It should be noted that the number of females participating in the study was much more than males, It is not a surprise, because, the number of females participated in the study was much more than the males ( $87.5 \%$ of participants).

A patient who had a keen interest in carpentry said that when she is engaged in her craft, she does not experience the effect of time. Some other patients who were interested in performing similar activities such as knitting were not able to do it due to financial problems and lack of equipment. Activities in this category are similar to those in some other instruments. For example those activities are under "creative activities" in Adolescence Leisure Interest Profile [37] and crafts in Assessing Adult Leisure Activities [27] and "crafts" in Assessing Adult Leisure Activities.

The fifth factor was named spiritual/ religious as religious structures and beliefs are an important part of most families belonging to this country. As such, activities related to this factor were considered by interviewees and researchers.

These activities can have an impact on a person. According to the interviews, activities related to this factor such as attending religious ceremonies may cause different reactions among persons. It is clear in the below sentence: "Someone say when we go to Rozeh (type of ceremony) our mood was worsen and depressed, But I am not alike. I'm well (when I go)"

Some of them expressed that they were willing to perform these activities while others were less interested in doing so. One of the reasons for this could be the spe- 
cialists' recommendation to not participate in religious activities as their psychological effects aggravate the disease. The spiritual/ religious factor was not found in other studies. This could probably be due to the fact that there is not much research in this field in countries such as Iran. We found going to church as an item in other research works but many items in our country can develop as separate factors. The last factor with the least frequency is educational, which is divided into two parts: teaching and learning. For example, "going to filmmaking class" and "teaching my niece".

It seems lack of interest and low frequency of participation in these activities is because of the progressive nature of the disease that increases inability, cognitive and emotional problems, and lack of time for beginning educational activities. We could not find this factor on other studies apart from Hosseini's study [16]. One of the women, who took part in the study and also had relatively little leisure time, said I am not interested in participating in leisure because of impatience and depression. She was crying. This represents the impact of psychological problems on participating in leisure.

\section{Conclusion}

From the findings of this study, we can conclude that the leisure activities of MS patients in Iran are influenced by six factors: social, individual, physical, art-cultural, spiritual/religious, and educational. The social factor is the most important as it demonstrates the significance of social life among MS patients. A variety of activities related to the spiritual/ religious factor are performed across the country, which can express a clear and separate factor.

The limitations of the study were the venue of interviews and the difficulties faced in accessing the patients. We suggest using the data derived from this study to develop a questionnaire about leisure activities of MS patients. We also suggest research be conducted on patients with other neurological and orthopedic disorders in order to form a comparison with this study.

\section{Acknowledgments}

We appreciate all the patients and the professionals who were involved in the study. This research project was financially supported by Hamedan University of Medical Sciences.

\section{Conflict of Interest}

The authors declared no conflicts of interest.

\section{References}

[1] Kielhofner G. A model of human occupation: Theory and application. Philadelphia: Williams \& Wilkins; 2002.

[2] Backman CL. Occupational Balance: Exploring the relationships among daily occupations and their influence on wellbeing. Canadian Journal of Occupational Therapy. 2004; 71(4):202-9. doi: 10.1177/000841740407100404

[3] Roley S, DeLany JV, Barrows C, Honaker D, Sava D, Talley $\mathrm{V}$, et al. Occupational therapy practice framework: Domain and process. The American Occupational Therapy Association. 2008; 62(6):625-83. PMID: 19024744

[4] Chang SC, Fang CL, Ling YC, Tsai BK. Effects of socioeconomic status on leisure volunteering constraint: A structural equation model. Social Behavior and Personality: An international Journal. 2011; 39(4):477-89. doi: 10.2224/ sbp.2011.39.4.477

[5] Agahi N. Leisure in late life: patterns of participation and relationship with health [MSc. thesis]. Stockholm: Karolinska Institutet; 2008

[6] Finlayson M, Impey MW, Nicolle C, Edwards J. Self-care, productivity and leisure limitations of people with multiple sclerosis in Manitoba. Canadian Journal of Occupational Therapy. 1998; 65(5):299-308. doi: 10.1177/000841749806500508

[7] Vanner EA, Block P, Christodoulou CC, Horowitz BP Krupp LB. Pilot study exploring quality of life and barriers to leisure-time physical activity in persons with moderate to severe multiple sclerosis. Disability and Health Journal. 2008; 1(1):58-65. doi: 10.1016/j.dhjo.2007.11.001

[8] Etemadifar M, Izadi S, Nikseresht A, Sharifian M, Sahraian MA, Nasr Z. Estimated prevalence and incidence of multiple sclerosis in Iran. European Neurology. 2014; 72(5-6):370-4. doi: $10.1159 / 000365846$

[9] Drummond AE, Parker CJ, Gladman JR, Logan PA. Development and validation of the Nottingham Leisure Questionnaire (NLQ). Clinical Rehabilitation. 2001; 15(6):647-56. doi 10.1191/0269215501cr438oa

[10] Khemthong S, Packer T, Passmore A, Dhaliwal S. Development of a Classification of Leisure Participation (CLP) scale Perceptions of leisure activities of women with and without chronic conditions. Paper presented at: The Mark Liveris Health Sciences Research Student Seminar 2005; 2005 August 6; Perth, Australia

[11] Packer TL, Boshoff K, DeJonge D. Development of the activity card sort-Australia. Australian Occupational Therapy Journal. 2008; 55(3):199-206. doi: 10.1111/j.14401630.2007.00686.x

[12] Passmore A, French D. Development and administration of a measure to assess adolescents' participation in leisure activities. Adolescence. 2001; 36(141):67-75. PMID: 11407636

[13] Khemthong S. The relationship between frequency and satisfaction of leisure participation and health-related quality of life in women with fatigue secondary to chronic illness $[\mathrm{PhD}$ thesis]. Perth: Curtin University; 2007.

[14] Walker GJ, Deng J, Dieser RB. Culture, self-construal, and leisure theory and practice. Journal of Leisure Research. 2005; 37(1):77-99. 
[15] Schultz-Krohn W, Pendelton H. Application of the occupational therapy practice framework to physical dysfunction. In: Williams Pedretti L, McHugh Pendleton H, Schultz-Krohn W, editors. Pedretti's Occupational Therapy for Physical Dysfunction. Amsterdam: Elsevier; 2006.

[16] Hosseini SMS, Asgari A, Rassafiani M, Yazdani F, Mazdeh M. Leisure time activities of Iranian patients with multiple sclerosis: A qualitative study. Health Promotion Perspectives. 2016; 6(1):47-53. doi: 10.15171/hpp.2016.08

[17] Shariati M, Dadgari A. [Designing, using and analyzing of qualitative research in health aspect and medical sciences (Persian)]. Tehran: Hayan. 2008.

[18] Zeighami R, Bagheri Nesami M, Oskouie F, Yadavar Nikravesh M. [Content analysis (Persian)]. Iran Journal of Nursing. 2008; 21(53):41-52

[19] Graneheim U, Lundman B. Qualitative content analysis in nursing research: Concepts, procedures and measures to achieve trustworthiness. Nurse Education Today. 2004; 24(2):105-12. doi: 10.1016/j.nedt.2003.10.001

[20] Javidan M, Dastmalchian A. Culture and leadership in Iran: The land of individual achievers, strong family ties, and powerful elite. Academy of Management Executive. 2003; 17(4):127-42. doi: 10.5465/ame.2003.11851896

[21] Foroghi N. [Leisure timeinSireand Sonnat. Farhang-eKosar (Persian)]. 2004; 58:21-28.

[22] Zamiri MR, RamzanNargesi R. [The role of the shi'ite faith in the cultural development of contemporary Iran (Persian)]. Shiite Studies. 2009; 7(27):113-56

[23] Scarmeas N, Levy G, Tang MX, Manly J, Stern Y. Influence of leisure activity on the incidence of Alzheimer's disease. Neurology. 2001; 57(12):2236-42. doi: 10.1212/wnl.57.12.2236

[24] Joudrey AD, Wallace JE. Leisure as a coping resource: A test of the job demand-control-support model. Human Relations. 2009; 62(2):195-217. doi: 10.1177/0018726708100357

[25] Leung GTY, Fung AWT, Tam CWC, Lui VWC, Chiu HFK, Chan WM, et al. Examining the association between late-life leisure activity participation and global cognitive decline in community-dwelling elderly Chinese in Hong Kong. International Journal of Geriatric Psychiatry. 2011; 26(1):39-47. doi: $10.1002 /$ gps.2478

[26] Lin MJ. A study on the relationships of service quality and satisfaction of leisure activities among the retired elderly in Caotun Town. Journal of Nan Kai. 2009; 6(2):39-48.

[27] Jopp DS, Hertzog C. Assessing adult leisure activities: An extension of a self-report activity questionnaire. Psychological Assessment. 2010; 22(1):108-20. doi: 10.1037/a0017662

[28] Hellström A, Hellström P, Willman A, Fagerström C. Associations between sleep disturbances and leisure activities in late-life. Sleep Medicine. 2013; 14:151-2. doi: 10.1016/j. sleep.2013.11.346

[29] Cheung M, Ting W, Chan L, Ho K, Chan W. Leisure participation and health-related quality of life of community dwelling elders in Hong Kong. Asian Journal of Gerontology \& Geriatrics. 2009; 4:15-23.

[30] Wang KH, Wang KM, editors. An Exploratory Study on Leisure Activities Demand of Elderly in Taiwan. Paper pre- sented at: The $10^{\text {th }}$ Academic and Business Research Institute Conference; 2011 October 6-8; Las Vegas, USA.

[31] Sered SS. Leisure participation and satisfaction in two European communities. Journal of Cross-Cultural Gerontology. 1987; 2(2):151-70. doi: 10.1007/bf00116670

[32] Bird CE, Fremont AM. Gender, time use, and health Journal of Health and Social Behavior. 1991; 32(2):114. doi: $10.2307 / 2137147$

[33] Iwasaki Y, Mannell RC, Smale BJ, Butcher J. Contributions of leisure participation in predicting stress coping and health among police and emergency response services workers. Journal of Health Psychology. 2005; 10(1):79-99. doi: $10.1177 / 1359105305048557$

[34] Garber CE, Friedman JH. Effects of fatigue on physical activity and function in patients with Parkinson's disease. Neurology. 2003; 60(7):1119-24. doi: 10.1212/01. wnl.0000055868.06222.ab

[35] Badia M, Orgaz MB, Verdugo MÁ, Ullán AM. Patterns and determinants of leisure participation of youth and adults with developmental disabilities. Journal of Intellectual Disability Research. 2012; 57(4):319-32. doi: 10.1111/j.13652788.2012.01539.x

[36] Paillard-Borg S, Wang HX, Winblad B, Fratiglioni L. Pattern of participation in leisure activities among older people in relation to their health conditions and contextual factors: A survey in a Swedish urban area. Ageing and Society. 2009; 29(5):803-21. doi: 10.1017/s0144686x08008337

[37] Trottier AN, Brown GT, Hobson SJG, Miller W. Reliability and validity of the Leisure Satisfaction Scale (LSS - short form) and the Adolescent Leisure Interest Profile (ALIP). Occupational Therapy International. 2002; 9(2):131-44. doi: 10.1002/oti.161 
